\title{
Evaluation on the Effects of the Frozen Pork Purchasing Policy on the Pork Price by ARMA
}

\author{
Z.Y.ZHU \& F.Y. NIE \& C.H QU\& L. ZHANG \& H.B. Zhu \& X.B. ZHANG \& Y.Z. CHU \\ Agricultural Information Institute, Chinese Academy of Agricultural Sciences (CAAS), Beijing 100081, \\ P.R.China
}

Key Laboratory of Agri-Information Service Technology, Ministry of Agriculture, Beijing 100081, P.R.China Correspondence to: Fengying Nie

\begin{abstract}
This paper studies the effects of frozen pork purchasing policy on the pork prices from 2009 to 2014 by Auto-Regressive and Moving Average Mode (ARMA). The results show that there are significant effects of froze pork purchasing policy on stabilizing the pork price and the pork price will uprising by 0.0563 Yuan per kilogram, while there are different effects among different years and the effects are becoming obvious as the time goes. The most significant effect is observed in 2014 , with the price uprising by 0.3110 Yuan per kilograms. The different effects among different years results from the purchasing rationing, purchasing times, information disclosure and acceptance by the market stakeholders. Thus the purchasing policy should be perfected in the volume, scale and underselling to maximize its influence on the stable pork price.
\end{abstract}

KEYWORD: Pork price; Frozen pork purchasing policy; ARMA; Effects

\section{INTRODUCTION}

It has been 6 years since the start of the frozen pork purchasing policy in April of 2009, which has been carried out for the first time on the April 13th, April 24th, May 20th and June 2nd of 2009, followed on April 3rd, April 20th, May 20th, June 2nd and June 30th in 2010, in April and August of 2012, April and May of 2013 and March and May of 2014 because of the falling of pork price. There are just a few qualitative description of its effects and few studies (Shu A.L., 2014 and Wang Y.M., 2010) try to quantify the policy effects on the pork market. In order to research and judge the influence of the frozen pork purchasing policy on stabilizing pig price and offer a proposal to perfect the frozen pork purchasing policy, the paper will analyze the pork price trend through comparing the price of the time before the government purchases and stores the frozen pork with the price of the time after the frozen pork purchasing policy comes into action.

\section{DATA AND EMPIRICAL METHODOLOGY}

\subsection{Data sources and analysis}

Weekly data on live pig prices and pork price from 2008 to 2014 were obtained from MOA of China.

\subsection{Empirical methodology}

In order to examine the autocorrelation of the time series data of pork price, the paper adopts the ARMA (p,q) to examine the autocorrelation of the residual sequence of the equation with lag dependent variable. The model of ARMA (p,q) is applied to correct the residuals autocorrelation of the regression equation in the paper.

$$
\begin{aligned}
& P O P_{t}=c_{0}+c_{1} P L P_{t}+c_{2} P O P_{t-1}+\cdots+c_{p} P O P_{t-p+1}+c_{p+1} P O l C_{t-1}+u_{t} \\
& u_{t}=\phi_{1} u_{t-1}+\phi_{2} u_{t-2}+\cdots+\phi_{3} u_{t-q}+\varepsilon_{t}
\end{aligned}
$$

In the formula, POP is the price of pork, and PLP as the pig price, POLC as the frozen pork purchasing policy, $\mathrm{t}$ as the time point, $u$ and $\varepsilon$ as the residual of the regression equation, $c$ and $\phi$ as the coefficient of the equation, and $\mathrm{p}$ and $\mathrm{q}$ as the order of the ARMA (p,q).

\section{EFFECTS OF POLICY ON THE PORK PRICE}

\subsection{Determination of Lag Time}

The frozen pork purchasing policy is implemented when the pork price is decreasing. The pork price was falling when the frozen pork purchasing policy into action 4 times in 2009 and the pork price started to rise in June when the pork price was at the lowest and the fourth purchasing policy starts. The same 
trend was observed in 2010, and 2012-14, respectively.

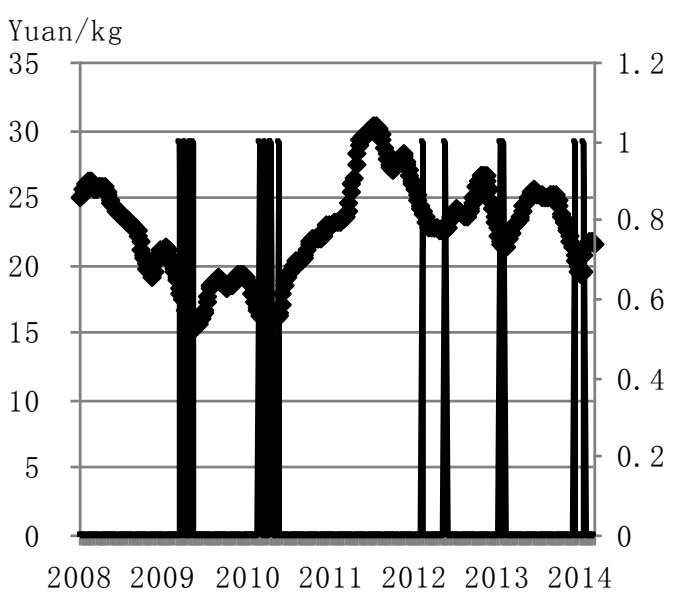

Figure 1.2 Weekly pork and pig prices and state purchasing point during 2009-2014

Firstly, the lag of policy variable of the frozen pork purchasing policy is determined by Akaike information criterion (AIC) and Bayesian Information Criterions (BIC) and 3 weeks are the most suitable in the model (Table 1). In practice, a policy will not play a role immediately when into action because of the lag phase. In the background of the currently simulated weekly price, the lags of 3 periods means that the effect of the national pork purchasing plan will appear one month later since it starts. The model can be inserted separate policy variable and cannot be applied to evaluate the effect of policy at lags of several periods because of the discrete distribution performance of policy variable.

Table 1 Test of lag time of policy variables for pork price

\begin{tabular}{|c|c|c|c|c|}
\hline Lag time & LR & Prob & AIC & SBIC \\
\hline 0 & & & 5.404 & 5.411 \\
\hline 1 & 1682.5 & 0 & 0.383 & 0.406 \\
\hline 2 & 476.56 & 0 & -1.034 & -0.999 \\
\hline 3 & $11.994 *$ & 0.001 & $-1.063 *$ & $-1.0179 *$ \\
\hline 4 & 0.3468 & 0.556 & -1.059 & -1.001 \\
\hline
\end{tabular}

\subsection{Effects of Frozen Pork Purchasing on Pork Price}

The regression results of the model of the national pork purchasing policy shows in Table 2 .

The POLC has a positive effect on the pork price 3 weeks later, and the price will have an increase of 0.0632 Yuan per kilogram .The boost of market confidence after the policy comes into action and the anticipation for the price of supplier and demander is reformulated and the regulation effect is showed.
Table 2 Results of Regression model

\begin{tabular}{|c|c|c|}
\hline variables & (1) & (2) \\
\hline \multirow{2}{*}{ PLP } & $0.2093 * * *$ & $0.3853 * * *$ \\
\hline & $(0.0188)$ & $(0.0427)$ \\
\hline \multirow{2}{*}{ POPt-1 } & $1.5880 * * *$ & $1.2058 * * *$ \\
\hline & $(0.0606)$ & $(0.1158)$ \\
\hline \multirow{2}{*}{ POPt-2 } & $-0.9498 * * *$ & $-0.6696 * * *$ \\
\hline & $(0.0918)$ & $(0.1478)$ \\
\hline \multirow{2}{*}{ POPt-3 } & $0.2158 * * *$ & $0.1915^{* * *}$ \\
\hline & $(0.0459)$ & $(0.0642)$ \\
\hline \multirow{2}{*}{ POLCt-3 } & $0.0632 *$ & \\
\hline & $(0.0339)$ & \\
\hline \multirow{2}{*}{ 2009POLCt-3 } & & $-0.0563 * * *$ \\
\hline & & $(0.0212)$ \\
\hline \multirow{2}{*}{ 2010POLCt-3 } & & 0.0097 \\
\hline & & $(0.0200)$ \\
\hline \multirow{2}{*}{ 2012POLCt-3 } & & $0.0962 * * *$ \\
\hline & & $(0.0178)$ \\
\hline \multirow{2}{*}{ 2013POLCt-3 } & & $0.1379 * * *$ \\
\hline & & $(0.0239)$ \\
\hline \multirow{2}{*}{ 2014POLCt-3 } & & $0.3110 * * *$ \\
\hline & & $(0.0620)$ \\
\hline \multirow{2}{*}{ Constant term } & $0.3508 * * *$ & $0.6794 * * *$ \\
\hline & $(0.0494)$ & $(0.0753)$ \\
\hline $\mathrm{R} 2$ & 0.9989 & 0.9992 \\
\hline $\mathrm{F}$ & 59366.91 & 63793.96 \\
\hline DW & 1.65 & 1.45 \\
\hline
\end{tabular}

\subsection{The Annual Variation of the Policy Effects}

In order to analyze the effect of the national pork purchasing plan further, the paper will estimate the effect of the policy implemented in different years through time series autoregressive model, which will adopt the POLC which has a lag of 3 weeks to keep the model consist. 2009POLCt, 2010POLCt, 2012POLCt, 2013POLCt and 2014POLCt stands for the frozen pork purchasing policy in 2009, 2010, 2012, 2013 and 2014, respectively.

According to the table 2, the coefficient of the POLC is -0.0563 in 2009 , illustrating that the pork price will still have a decrease of 0.0563 Yuan per kilogram 3 weeks after the policy action. In 2009, the pork price had been decreased for 19 weeks and thus the frozen pork purchase had been carried out 4 times. The pork output in 2009 was increased by $5.8 \%$ than previous year, and the pork price was decreased for oversupply. The coefficient of the POLC in 2010 is 0.085 , indicating the pork price increase of 0.0097 Yuan per kilogram, while it is not significant. The frozen pork price purchasing had been carried out for 5 times at that year. Thus the ratio of pig to maize price had been below $6: 1$ for 32 weeks, among which there were 15 weeks below $5: 1$, and it resulted in the quitting of pig production 
of many producers and the pork price was continually uprising till September of 2011. In 2012, the national pork purchasing plan had remarkable influence on the pork price and the coefficient of the POLC was significant, at 0.0962 . The effects are even more significant in 2013 and 2014, with the coefficients at 0.1379 and 0.3110 , and it means the pork prices are increased by 0.1379 and 0.3110 Yuan per kilogram, respectively.

\section{CONCLUSION}

It has proved that the frozen pork purchasing policy plays a positive role in protecting the interest of pork producers and its influence is increased as time goes. When the national pork purchasing plan was carried out firstly in 2009, the confidence coming from market was not gained instantly for lower volume in 4 times of purchasing and the main determination factors of pork price were still supply and demand, and the limited volume of frozen purchase has no powerful ability to adjust the market supply of pork. In 2010, the effects of pork purchasing were not significant at first, while the stimulation of the confidence to the market participants was observed after another 4 purchasing of frozen pork. It suggests there is a period of time before the effects of policy on the market shows. After 2011, the purchasing of froze pork was carried out twice annually when the ratio of pig to maize price at less than $6: 1$ for more than 10 week, and the effects are becoming more obvious compared to the previous 2 years.

The policy should be adjusted to better control the pork market. Firstly, the augmented pork purchasing volume and scale should be put into effect. In 2009 and 2010, the purchase amount was divided in 4 and 5 parts, respectively, and for example, the first purchase amount of frozen pork in 2010 was just 3000 tons and the purchase was specifically assigned to Yunnan province under heavily drought. After the policy was perfected to increase the purchase amount and decrease purchase times, and the better effects was observed.

The disclosure of purchase information of frozen pork to public, especially to the pig farmer shows influence on the policy effects on the pork market. The information of purchasing frozen pork could be obtained publicly is just when is purchasing is carried out, and the purchased volume and where to purchase or by which enterprise were still unknown before 2013. In 2013 and 2014, the purchase time and volume of frozen pork were reported, and especially in 2014, before the second purchase on the May 8th, the pork price began to stabilize and sharply increase after the information of 88 thousands tons purchased frozen pork announced.

\section{POLICY SUGGESTION}

The purchase amount and scale of stored frozen pork should be increased and the national frozen storage ability should be promoted as an adjusting tool of market. The experience of other countries could be as reference. For example, Japan government purchases and stores 25 percent of the total output of pork every year, and the proportion is $5 \%$ in the U.S.A, while that in China is less than 200 thousand tons, less than $0.4 \%$ of the total pork output in China. The key to strengthen the effect of the national pork purchasing and storage plan on stimulating the depressed pork market is augmented pork purchased volume and appropriate scale of the purchased and stored pork in the pork market. Compared with the massive produced and consumed pork volume, the produced pork volume of the U.S.A is only equivalent to the $1 / 5$ of China. But the storage volume of frozen pork of the U.S.A is far more than the storage volume of China, and the storage volume will increase or decrease along with the pork price falling or rising.

The national pork purchasing and storage plan should be implemented with other measure to regulate the pork market. The pork purchasing could not change the structure of demand and supply and should be implemented in combination of policies on pig production. It will stimulate pork production and prevent the recession of pork production to provide subsidy for reproductive sows to pig producer before the ratio of pig to maize falls to the primary level. The lessons could be learned in the pork market of 2009, in which the subsidy of sows was suspended. However, the most important is that the amount of sows receiving subsidy should be controlled according to certain quartos in order to protect from oversupply.

The certain amount of purchased frozen pork is suggested to be distributed to the students and poverty group to ease the negative effect caused by underselling frozen pork. The paper suggests that the government should adopt the non open-market operations, undersell the frozen pork to some specific enterprises confidentially, or provide the pork to low-income group for free. All the measures will prevent the negative effect caused by underselling frozen pork to market directly.

\section{REFERENCES}

[1] Shu, A.L. 2014. Effects of National Frozen Pork Storage Policy on the Market. China Animal Health (5): 9-10.

[2] Wang, Y.M. 2010. Reasons under the $5^{\text {th }}$ Fronze Pork Puchasing. Modern Livestock and Poultry Breeding Industry (8): 61 . 